\title{
Short communication: Relationship of activity and rumination to abundance of pest flies among organically certified cows fed 3 levels of concentrate
}

\author{
L. S. Sjostrom, ${ }^{*}$ B. J. Heins, ${ }^{* 1}$ M. I. Endres, ${ }^{*}$ R. D. Moon, $†$ and J. C. Paulson \\ *Department of Animal Science, and \\ †Department of Entomology, University of Minnesota, St. Paul 55108 \\ fUniversity of Minnesota Extension, Rochester 55904
}

\section{ABSTRACT}

The objectives of this study were to evaluate activity, rumination time, and their association with 3 kinds of pasture flies for organic dairy cows $(\mathrm{n}=57)$ fed 3 grain supplementation strategies during the grazing season from May to September 2013. Cows were assigned to 1 of 3 replicate supplementation groups: (1) no corn-grain supplementation (100\% pasture, PAS, n $=19)$; (2) low corn-grain $(2.72 \mathrm{~kg} /$ cow per day, LG, n $=19)$; and (3) high corn-grain $(5.44 \mathrm{~kg} / \mathrm{cow}$ per day, $\mathrm{HG}, \mathrm{n}=19$ ). Cows calved during 2 seasons (fall and spring) at the University of Minnesota West Central Research and Outreach Center, Morris, from October to December 2012 and March to May 2013. Supplement (corn-grain and minerals) was fed in a total mixed ration of corn silage and alfalfa silage, and at least $30 \%$ of diet dry matter intake for LG and HG cows consisted of pasture. Activity and rumination time (daily and 2-h blocks of time) were monitored electronically using HRLD tags (SCR Engineers Ltd., Netanya, Israel) for 125 d. Activity (cow body movement and head movement) was reported in activity units from SCR DataFlow II software, and rumination times were reported in minutes per day. PROC HPMIXED in SAS (SAS Institute Inc., Cary, NC) was used for statistical analysis, and independent variables were season of calving (fall or spring), month of grazing (June to September), supplementation group, and interactions of month of grazing and supplementation group. Replicate was a random effect with repeated measures. Daily activity was higher for PAS cows (1,138 activity units) than for HG cows (1,001 activity units), and LG cows (1,019 activity units). Daily activity was highest in July (1,258 activity units) and lowest in September (819 activity units). Rumination was not different for PAS (397 min/d), LG $(384 \mathrm{~min} / \mathrm{d})$, or HG $(370 \mathrm{~min} / \mathrm{d})$ cows. Daily rumination was greater in September (402 min/d) than in July

Received February 16, 2016.

Accepted August 10, 2016.

${ }^{1}$ Corresponding author: hein0106@umn.edu

(361 $\mathrm{min} / \mathrm{d})$. Daily activity increased rapidly between 0600-0800 h and 1600-1800 h. From 1800 to 2000 h, cows had a rapid decline in activity until $0600 \mathrm{~h}$ the next day. All supplementation groups had the greatest rumination activity from 0200 to $0400 \mathrm{~h}$ and the least between 1000 and $1200 \mathrm{~h}$. Greater activity of cows on a herd basis was moderately correlated with increased fly populations. Monthly activity patterns of grazing cows were associated with fly populations on cows.

Key words: activity, rumination, organic, grass-fed

\section{Short Communication}

Activity and rumination monitoring systems (ARS) are growing in popularity in the global dairy industry. These monitoring systems are becoming more feasible for dairy producers to adopt as part of their management enterprise because of the rapid development of precision dairy technologies.

The ARS may help small and organic dairy producers achieve superior pregnancy rates without the use of reproductive hormones and they may help identify unhealthy cows. They may be beneficial for small dairy herds where labor is not available to watch cows for mounting behavior, especially useful for organic dairies in the United States, because they are not allowed to use reproductive hormones as part of their management procedures (USDA-NOP, 2015).

These ARS are used more commonly in confinement dairy operations, and very little research has been conducted in grazing environments; however, a few studies have been conducted in New Zealand (Kamphuis, et al., 2012; Elischer et al., 2013; Gregorini et al., 2013). Schirmann et al. (2009) reported that ARS accurately measured rumination time in adult dairy cattle. Elischer et al. (2013) found that ARS reflected cow walking and rumination in a pasture-based dairy herd in the United States, but not with high accuracy. However, that study concluded that the ARS activity index did not distinguish between walking and lying behavior (Elischer et al., 2013). For pasture-based dairies, cows regulated their rumination time to compensate for man- 
agement styles that restricted grazing time (Gregorini et al., 2012), and daily rumination was not different for alternative breeds of cows or cows with varying genetic merit on pasture (Gregorini et al., 2013).

The horn fly is an important pest in pastured dairy cattle, because flies decrease milk production and reduce pasture intake (Denning et al., 2014). Furthermore, horn flies and stable flies reduce milk production and overall farm profitability (Taylor et al., 2012; Mays et al., 2014). Pasture fly-control measures are applied on $89 \%$ of organic dairy herds in Minnesota (Sorge et al., 2015), but fly management of pastured cattle is a growing problem, and many farmers rely on essential oil repellents to alleviate fly problems. Pasture cattle exhibit many different fly-avoidance behaviors, including head tossing, foot stomping, and bunching, and these can lead to decreased grazing time (Hart, 1994). Pasture flies may also affect the movement of the neck-collar-attached ARS; however, no research has determined the effect of flies on activity and rumination in a pasture-based grazing system.

The objectives of this study were to determine activity and rumination time in dairy cows fed 3 supplementation strategies during the grazing season and to correlate activity and rumination time with pasture fly populations using an automatic ARS.

Fifty-seven organically certified dairy cows from the University of Minnesota West Central Research and Outreach Center, Morris, were split into 3 replicated groups (2 replicates per supplementation group; 6 total groups of cows on pasture) grazing side by side during the summer of 2013. The first replicate of each treatment contained 10 cows, and the second replicate contained 9 cows. Cows were blocked by lactation number, season of calving (fall or spring), breed group, and previous lactation milk production, and all treatment groups contained both fall- and spring-calving cows. Breed groups of cows included pure Holsteins and various crossbreds of Jersey, Normande, Holstein, Montbéliarde, and Swedish Red; breed groups were balanced across treatment groups and replicates. Cows were fed the following dietary supplementation levels: (1) no grain supplementation ( $100 \%$ pasture, PAS, $\mathrm{n}=19$ cows); (2) low grain (LG, $2.72 \mathrm{~kg}$ of grain supplementation per day, $\mathrm{n}=19$ cows); or (3) high grain (HG, 5.45 $\mathrm{kg} / \mathrm{d}, \mathrm{n}=19$ cows). Supplement was fed with a TMR that included organic corn silage, alfalfa silage, and the corn-grain mix. On a DM basis per cow per day, the TMR was $4.24 \mathrm{~kg}$ of corn silage, $3.66 \mathrm{~kg}$ of alfalfa silage, and $0.65 \mathrm{~kg}$ of minerals. The partial TMR was fed in a barn after the morning milking, but LG and HG cows were allowed to graze in the afternoon and overnight. The PAS cows were continually on pasture, except during milking. For all cows, at least $30 \%$ of their diet consisted of high-quality pasture during the grazing season. All 6 groups of cows grazed alongside each other in the same pasture (divided into 6 paddocks using fencing), consisting mainly of smooth bromegrass, orchardgrass, timothy, alfalfa, and red and kura clover. Cows were moved to pasture on May 28, 2013, and grazing ended on September 30, 2013. Cows were in each replicated supplementation group for $24 \mathrm{~h}$ per day for the entire $125 \mathrm{~d}$ of the study, and the 6 replicate groups were brought separately to the milking parlor for the morning and evening milkings throughout the study. All groups of cows were stocked at a rate of 3 cows/ha and were simultaneously rotated to new paddocks every $2 \mathrm{~d}$ based on forage availability determined by visual observation or a Filip's electronic rising plate meter (Jenquip; NZ Agriworks Ltd., Feilding, New Zealand). Cows' average BW was $496 \mathrm{~kg} \pm 72.5 \mathrm{~kg}$, and their average lactation number was 2.6.

The organic dairy herd located at the University of Minnesota has 120 milking cows. Cows calve seasonally (September to November and March to May) each year. The summer partial TMR usually contains less forage, because cows have to consume at least $30 \%$ of their DMI from pasture, according to organic rules. Depending on the weather each year, the grazing season is typically May to October. Cows are usually on pasture for 16 to $22 \mathrm{~h}$ each day. Winters may be very cold and windy in western Minnesota, and cows typically have no pasture access from November to April.

All 57 animals were fitted with an HR-LD activity and rumination monitoring collar (SCR Engineers, Netanya, Israel) around the neck (Schirmann, et al., 2009). The SCR Heattime ARS (SCR Engineers) uses a 3 -axis accelerometer to monitor head and neck movements to develop an activity index for each cow. All animal movements are quantified in 2-h blocks of time (Aungier et al., 2012; Dolecheck et al., 2015). A microphone containing a microprocessor is used to determine rumination (Dolecheck et al., 2015). Because of the manufacturer's settings, the ARS collect data for $7 \mathrm{~d}$ before calculating a baseline activity and rumination index. The neck monitors record $24 \mathrm{~h}$ of data and communicate with the data recorder via a long-distance antenna placed on top of the milking center. The antenna had a range of several hundred meters, depending on the weather and other environmental factors. Each time the cattle returned to the milking center, and if they were in paddocks near the milking center, the antenna would download data as often as every 20 min. The ARS did not distinguish between walking and lying. Cows were milked in a swing-9 para-bone milking parlor at 0600 and $1700 \mathrm{~h}$. All animal procedures 
involving animal care and management were approved by the University of Minnesota Institutional Animal Care and Use Committee (\#1201B09304).

Trained observers counted the numbers of flies on every cow between 1300 and $1500 \mathrm{~h}$ on Mondays during the grazing season. Fly identification and counting methods were similar to those used by Denning et al. (2014). Observers distinguished horn flies (Haematobia irritans [L.]) from face flies (Musca autumnalis DeGeer) and stable flies (Stomoxys calcitrans [L.]). Horn flies were counted individually or in groups of 10 on 1 side of each cow. Face flies were counted on the animals' faces viewed head on, from poll to jawline and muzzle. Stable flies were counted on the visible faces of front and rear legs separately. Counts were made from a distance of 2 to $4 \mathrm{~m}$ (Watson et al., 2002; Denning et al., 2014).

Independent variables for statistical analysis of daily activity, daily rumination, activity in 2 -h blocks of time, and rumination in 2-h blocks of time were effects of month, supplementation group, and the interactions of month and supplementation group. Replicate was a random effect, with measurement date as repeated measures. For activity and rumination in 2-h blocks of time, 2-h blocks of time and the interactions of $2-\mathrm{h}$ blocks of time and supplementation group, and 2-h blocks of time and month and supplementation group were added to the model. The autoregressive covariance $[\operatorname{AR}(1)]$ structure was used because it resulted in the lowest Akaike's information criterion (Littell et al., 1998). The HPMIXED procedure in SAS (version 9.4; SAS Institute Inc., Cary, NC) was used to obtain solutions and conduct the ANOVA. All observations within replicates and dates, as well as replicate and 2-h blocks of time, were averaged for analyses. Replicate pen of cows on pasture was the experimental unit for analysis. All treatment results were reported as least squares means, with significance declared at $P<0.05$.

Daily activity and rumination variables were paired with number of flies observed on cows. For the analysis of fly population relationships using regression analysis, we compared the mean number of horn, stable, and face flies for supplementation groups. Independent variables were the effects of supplementation group, and replicate was a random effect, with measurement data as repeated measures. The autoregressive covariance $[\operatorname{AR}(1)]$ structure was used (Littell et al., 1998). Furthermore, linear regression analysis was used to estimate the relationships between fly populations and daily activity and rumination variables. Daily activity and rumination variables were regressed on horn, stable, and face fly number for each supplementation group, and replicate was a random effect in the model. We used the MIXED procedure in SAS (version 9.4;
SAS Institute Inc.) to obtain solutions and conduct the ANOVA. We also calculated Pearson correlation coefficients using PROC CORR in SAS.

The milk production of the cows in this study has been reported by Heins et al. (2014); the PAS cows had lower ECM $(14.4 \mathrm{~kg} / \mathrm{d} ; P<0.05)$ than the LG $(16.2$ $\mathrm{kg} / \mathrm{d})$ and HG $(17.0 \mathrm{~kg} / \mathrm{d})$ cows, but the LG and HG cows did not differ from each other. The interactions of month and supplementation group, 2-h blocks of time and supplementation group, and 2-h blocks of time and month and supplementation group also significantly explained variation $(P<0.01)$ in activity and rumination of grazing cattle.

For daily activity by month across supplementation groups (Table 1), cows in July had greater activity $(1,258$ units; $P<0.05)$ than cows in June (1,032 units), August (1,101 units), and September (819 units). For daily rumination, cows in September had greater rumination time $(402 \mathrm{~min} / \mathrm{d} ; P<0.05)$ than cows in June (377 min/d), July (361 min/d), and August (395 $\min / d)$. Rumination decreased during July but rumination increased during August and September. Throughout the current grazing study, the correlation of daily activity and rumination was -0.60 .

Least squares means and standard errors for daily activity and rumination for grazing month and supplementation group are shown in Table 1. For supplementation groups across months, the PAS cows had greater daily activity $(1,138$ units; $P<0.05)$ than the HG $(1,001)$ cows, simply because they were on pasture longer during the day. The LG and HG cows did not differ in daily activity. Surprisingly, average daily rumination was not different among supplementation groups, at $397 \mathrm{~min} / \mathrm{d}$ for the PAS cows, $384 \mathrm{~min} / \mathrm{d}$ for the LG cows, and 370 $\mathrm{min} / \mathrm{d}$ for the HG cows, with an overall average of 384 $\mathrm{min} / \mathrm{d}$. These results are lower than those reported by Gregorini et al. (2013), but the differences can likely be attributed to differences in grazing systems and grass species between New Zealand and the United States.

The PAS cows had greater $(P<0.05)$ daily activity during June, August, and September than the LG and HG cows. The PAS cows may have been expected to have greater activity because of greater time spent grazing on average and the need to consume ungrazed pasture within a paddock. The reason for the varying daily activity among months may have been due to forage availability, ambient temperature, weather events, fly pressure, the distance cows walked to the milking parlor every day, or other factors. The ARS monitor output data did not distinguish between walking and lying time, so walking time and distance could not be assessed. The differences among supplementation groups was likely because of time spent grazing and a 
greater percentage of DMI coming from pasture for the PAS cows. Daily rumination by month was not different for supplementation groups.

Figure 1 shows means for activity by 2 -h blocks of time, and Figure 2 shows means for rumination by 2-h blocks of time for the PAS, LG, and HG supplementation groups. Activity levels increased in all cows throughout the day, starting at $0400-0600 \mathrm{~h}$ up to 1800 h. The PAS cows had greater activity $(P<0.05)$ during the early morning and early evening hours because of movement to the milking parlor and back to the grazing paddock. Activity levels decreased markedly after $1800 \mathrm{~h}$ and remained low through $0400 \mathrm{~h}$. For rumination across $24 \mathrm{~h}$ (Figure 2), the PAS cows had greater $(P<0.05)$ rumination from 0200 to $0400 \mathrm{~h}$ than the LG or HG cows. Surprisingly, the LG cows had greater $(P<0.05)$ rumination per hour from 1000 to $1400 \mathrm{~h}$ than the PAS cows; this result was unexpected because LG cows were in the same feeding and housing environment during the day. All of the supplementation groups ruminated during the night and remained active during the day (Figures 1 and 2), possibly contradicting the notion that the PAS cows would rest during the hottest portion of the day and consume more DM during the night. Nonetheless, these results were similar to those of Gregorini et al. (2013), who reported that cows grazing during the spring months in New Zealand had greater rumination per hour during the night and early morning than during the day.

Mean number of flies per cow by group, and regression coefficients and Pearson correlation coefficients for daily activity and rumination and numbers of horn, face, and stable flies for supplementation groups are summarized in Table 2. Unadjusted fly counts ranged from 0 to 400 flies per side for horn flies. Front and rear leg counts ranged 0 to 67 for stable flies, and face counts ranged from 0 to 35 for face flies. We observed a tendency for the PAS $(59.2$ flies/cow; $P<0.10)$ cows to have more horn flies than the LG cows (41.2 flies/ cow) and HG cows (43.2 flies/cow). The PAS cows had greater numbers of face flies and stables files (4.5 face flies/cow and 12.8 stable flies/cow; $P<0.05)$ than the LG cows (3.1 face flies/cow and 9.4 stable flies/cow) and the HG cows (3.1 face flies/cow and 8.6 stable flies/cow).

Based on the regression analysis, for every 1 additional horn fly on a specific PAS cow, activity units increased by $1.02(P<0.07)$. Activity units increased by $1.97(P<0.01)$ for every additional horn fly on a LG cow. Activity units were not affected by horn fly numbers on the HG cows. Neither face flies nor stable flies affected $(P>0.12)$ activity units for any supplementation group. Similarities existed for daily rumination, but only in the PAS cows did horn flies (no stable or face flies) affect it (Table 2).

For the correlation analysis, an increase in number of horn flies was not associated with activity levels for PAS cows; however, a greater number of horn flies on LG and HG cows was associated $(P>0.05)$ with activity levels. An increase in horn fly numbers may not have been associated with the activity of the PAS cows compared with the LG and HG cows because the PAS cows grazed more during the day than the LG and HG cows. The activity of the LG cows was associated with numbers of stable flies, but the activity levels of the PAS and HG cows tended $(P<0.10)$ to be associated

Table 1. Least squares means and standard errors for daily activity and rumination for grazing month and supplementation group [no grain supplement (100\% pasture), a low level of grain supplementation, or a high level of grain supplementation]

\begin{tabular}{|c|c|c|c|c|c|c|c|c|}
\hline \multirow[b]{2}{*}{ Item } & \multicolumn{2}{|c|}{$\begin{array}{c}\text { Across } \\
\text { supplementation groups }\end{array}$} & \multicolumn{2}{|c|}{$100 \%$ pasture } & \multicolumn{2}{|c|}{ Low supplement } & \multicolumn{2}{|c|}{ High supplement } \\
\hline & Mean & $\mathrm{SE}$ & Mean & $\mathrm{SE}$ & Mean & $\mathrm{SE}$ & Mean & $\mathrm{SE}$ \\
\hline \multicolumn{9}{|l|}{ Daily activity $^{1}$} \\
\hline June & $1,032^{\mathrm{c}}$ & 30.9 & $1,175^{\mathrm{a}}$ & 46.1 & $985^{\mathrm{b}}$ & 67.8 & $935^{\mathrm{b}}$ & 43.5 \\
\hline July & $1,258^{\mathrm{a}}$ & 30.9 & $1,280^{\mathrm{a}}$ & 46.1 & $1,264^{\mathrm{a}}$ & 67.9 & $1,230^{\mathrm{a}}$ & 43.6 \\
\hline August & $1,101^{\mathrm{b}}$ & 31.2 & $1,189^{\mathrm{a}}$ & 46.3 & $1,053^{\mathrm{b}}$ & 68.5 & $1,063^{\mathrm{b}}$ & 43.9 \\
\hline \multicolumn{9}{|l|}{ Daily rumination $^{2}$} \\
\hline June & $377^{\mathrm{c}}$ & 24.8 & 380 & 24.8 & 373 & 36.9 & 378 & 23.3 \\
\hline July & $361^{\mathrm{d}}$ & 24.8 & 380 & 24.8 & 357 & 36.9 & 344 & 23.3 \\
\hline August & $395^{\mathrm{ab}}$ & 24.8 & 412 & 24.8 & 396 & 37.1 & 376 & 23.4 \\
\hline September & $402^{\mathrm{a}}$ & 25.0 & 417 & 25.0 & 408 & 37.2 & 382 & 23.7 \\
\hline Across 4-mo period & & & 397 & 24.3 & 384 & 36.7 & 370 & 22.9 \\
\hline
\end{tabular}

\footnotetext{
${ }^{a-d}$ Means within a row for daily activity with different superscripts are different at $P<0.05$.

${ }^{1}$ Activity is presented as activity units.

${ }^{2}$ Rumination is $\min / \mathrm{d}$. No significant difference was observed between treatment groups for daily rumination for months and across month of grazing.
} 


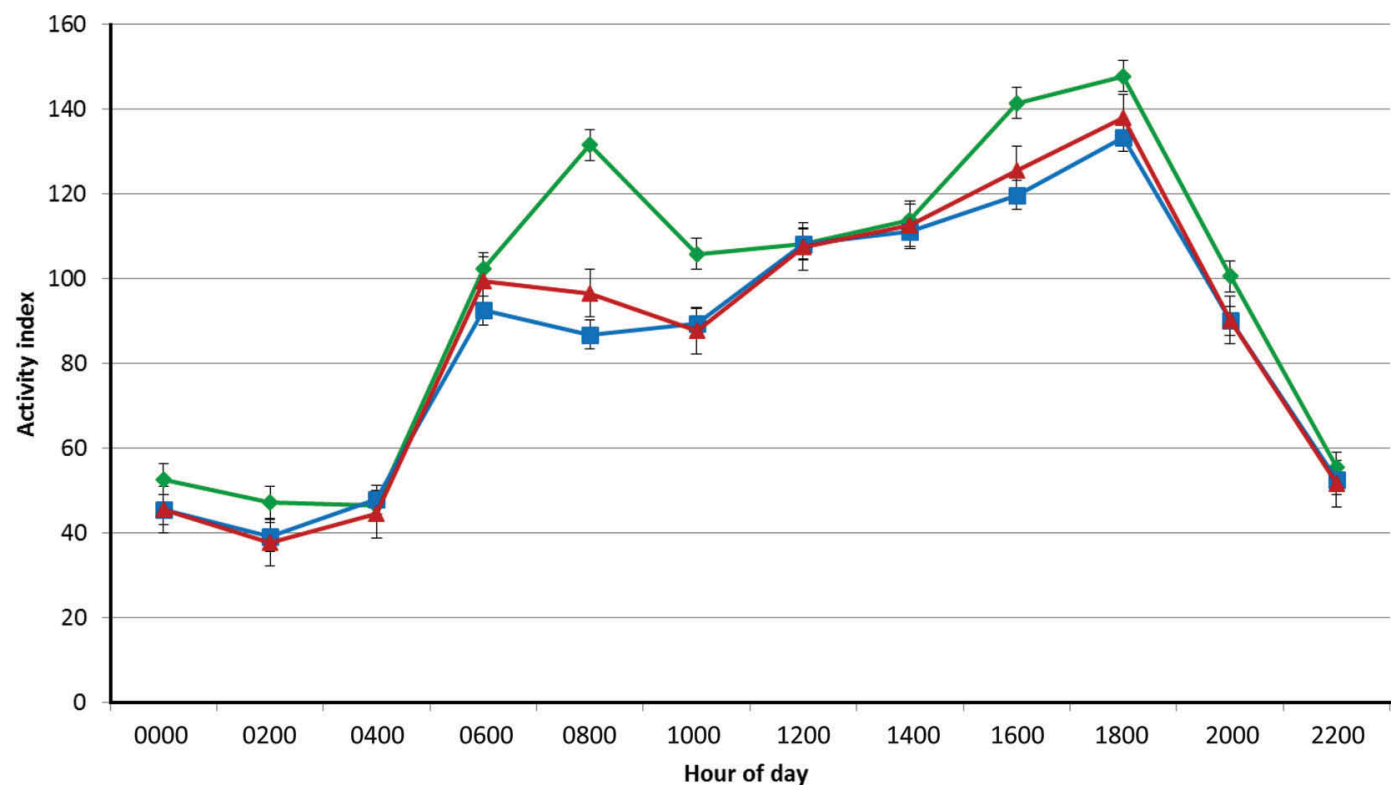

Figure 1. Activity index of cows in 2-h increments. Cows were fed no grain supplement (100\% pasture, PAS, $\bullet$ ), a low level of grain supplementation (LG, $\mathbf{\Delta}$ ) or a high level of grain supplementation (HG, $\mathbf{a})$. Least squares means and SE bars for activity index by 2 -h blocks of time averaged across the entire 2013 grazing season (May to October) for PAS, LG, and HG dairy cows. The PAS cows were significantly $(P<0.05)$ different from the LG cows at $8,10,16,18$, and $20 \mathrm{~h}$, and significantly $(P<0.05)$ different from the HG cows at $6,8,10,16,18$, and 20 h. The LG and HG cows were not different at any specific time point. Color version available online.

with the number of stable flies. Face flies were not associated with activity in any of the supplementation groups.
Daily rumination time in the PAS cows was inversely correlated with numbers of horn flies $(\mathrm{r}=-0.48, P$ $<0.01$ ), but rumination times in the other 2 groups

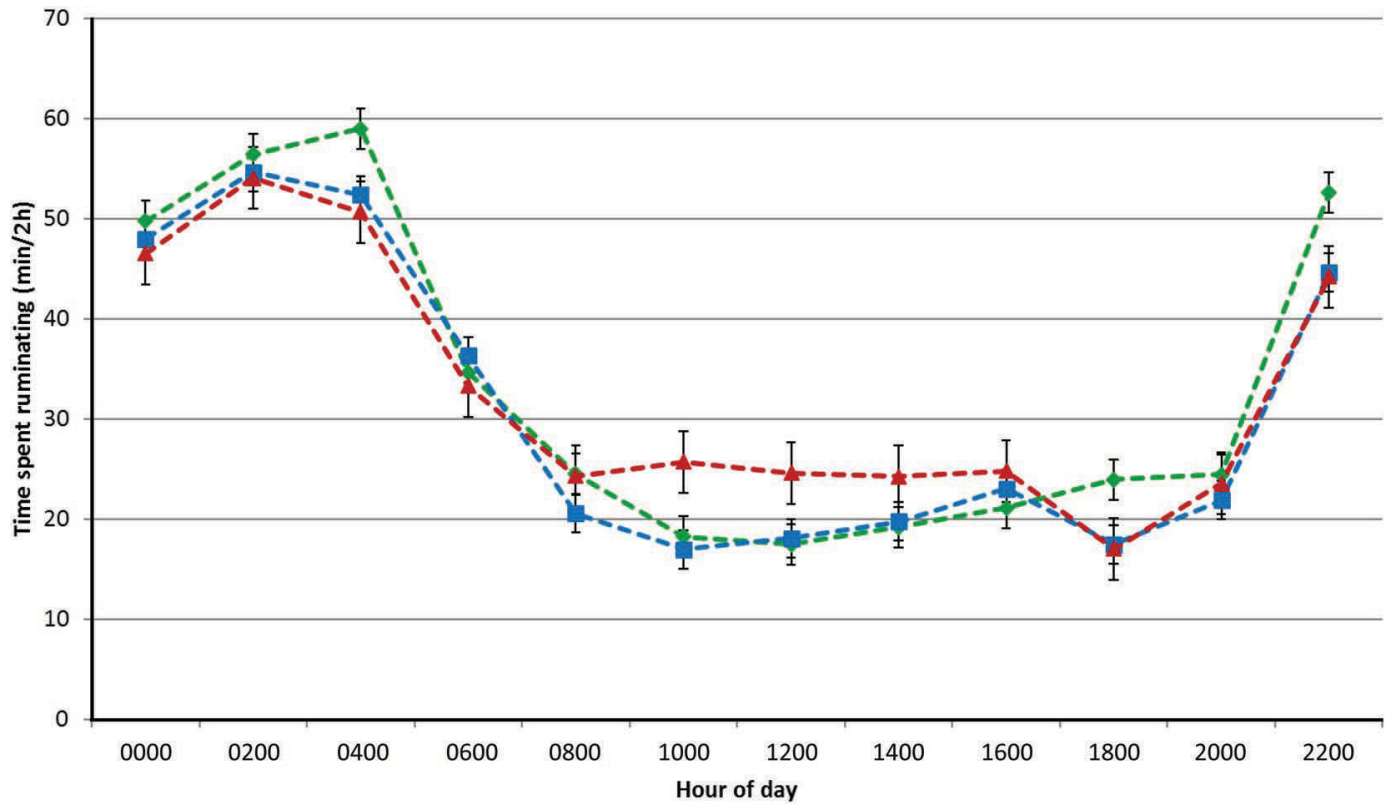

Figure 2. Rumination time of cows in 2-h increments. Cows were fed no grain supplement (100\% pasture, PAS, $\bullet$ ), a low level of grain supplementation (LG, $\mathbf{\Delta}$ ) or a high level of grain supplementation (HG, $\mathbf{0})$. Least squares means and SE bars for rumination (min) by 2-h blocks of time averaged across the entire 2013 grazing season (May to October) for PAS, LG, and HG dairy cows. The PAS cows were significantly ( $P$ $<0.05$ ) different from the LG cows at 4,10,12, 18, and $22 \mathrm{~h}$, and from the HG cows at 4, 18, and $22 \mathrm{~h}$. The LG and HG cows were different only at $10 \mathrm{~h}$. Color version available online. 
Table 2. Mean number of flies per cow by supplementation group [no grain supplement (100\% pasture), a low level of grain supplementation or a high level of grain supplementation], and regression coefficients and Pearson correlation coefficients for daily activity, rumination, and numbers of horn, face, and stable flies

\begin{tabular}{|c|c|c|c|c|c|c|}
\hline Item & \multicolumn{2}{|c|}{$100 \%$ pasture } & \multicolumn{2}{|c|}{ Low supplement } & \multicolumn{2}{|c|}{ High supplement } \\
\hline $\begin{array}{l}\text { Daily activity } \\
\text { Horn flies } \\
\text { Face flies } \\
\text { Stable flies }\end{array}$ & $\begin{array}{l}1.02 \\
2.30 \\
0.75\end{array}$ & $\begin{array}{l}0.07 \\
0.62 \\
0.78\end{array}$ & $\begin{array}{l}1.97 \\
0.41 \\
0.75\end{array}$ & $\begin{array}{l}0.01 \\
0.92 \\
0.72\end{array}$ & $\begin{array}{l}-0.4 \\
-6.6 \\
-2.6\end{array}$ & $\begin{array}{l}0.50 \\
0.12 \\
0.21\end{array}$ \\
\hline $\begin{array}{l}\text { Daily rumination } \\
\text { Horn flies } \\
\text { Face flies } \\
\text { Stable flies }\end{array}$ & $\begin{array}{l}0.51 \\
1.33 \\
2.47\end{array}$ & $\begin{array}{l}0.01 \\
0.30 \\
0.01\end{array}$ & $\begin{array}{l}0.56 \\
1.38 \\
1.21\end{array}$ & $\begin{array}{l}0.10 \\
0.63 \\
0.34\end{array}$ & $\begin{array}{c}0.09 \\
3.0 \\
-0.76\end{array}$ & $\begin{array}{l}0.76 \\
0.19 \\
0.50\end{array}$ \\
\hline $\begin{array}{l}\text { Daily activity } \\
\text { Horn flies } \\
\text { Face flies } \\
\text { Stable flies }\end{array}$ & $\begin{array}{r}0.22 \\
-0.06 \\
0.14\end{array}$ & $\begin{array}{l}0.28 \\
0.59 \\
0.10\end{array}$ & $\begin{array}{l}0.61 \\
0.02 \\
0.43\end{array}$ & $\begin{array}{l}0.001 \\
0.94 \\
0.03\end{array}$ & $\begin{array}{r}0.40 \\
-0.28 \\
0.33\end{array}$ & $\begin{array}{l}0.05 \\
0.16 \\
0.10\end{array}$ \\
\hline $\begin{array}{l}\text { Daily rumination } \\
\text { Horn flies } \\
\text { Face flies } \\
\text { Stable flies }\end{array}$ & $\begin{array}{r}-0.48 \\
0.25 \\
-0.23\end{array}$ & $\begin{array}{l}0.01 \\
0.21 \\
0.26\end{array}$ & $\begin{array}{r}-0.25 \\
0.13 \\
0.31\end{array}$ & $\begin{array}{l}0.21 \\
0.54 \\
0.11\end{array}$ & $\begin{array}{r}-0.04 \\
0.27 \\
-0.15\end{array}$ & $\begin{array}{l}0.86 \\
0.18 \\
0.46\end{array}$ \\
\hline
\end{tabular}

${ }^{\mathrm{a}, \mathrm{b}}$ Means within a row with different superscripts are different at $P<0.05$.

$\dagger$ Means within a row for horn flies were different at $P<0.10$.

were not associated with horn fly numbers. Rumination times were not associated $(P>0.11)$ of numbers of face flies and stable flies in any of the supplementation groups.

We expected the negative association between number of pasture flies and rumination time to be greater. However, rumination in cows was greatest during the evening hours, when fly pressure was not expected to be high. Boland et al. (2008) reported an increase in fly-avoidance behaviors with an increase in fly pressure. The ARS may have been detecting fly-avoidance behaviors (i.e., head throws) instead of grazing activity. Decreasing fly pressure should promote animal wellbeing and reduce fly-avoidance behaviors, as well as increasing cows' grazing time. Schmidtmann et al. (1981) reported a grazing time reduction with the increased presence of face flies.

The results of this study suggest that cows that spend most of their day on pasture have increased daily activity levels; however, daily rumination was not different between cows that consumed $100 \%$ pasture compared with cows that were supplemented on pasture with a partial TMR. Higher horn fly populations were associated with decreased rumination in dairy cattle on pasture over almost $24 \mathrm{~h}$; this may lead to reduced milk production and well-being in grazing dairy cattle. Dairy producers must carefully design grazing management, facilities, and nutritional feeding systems to ensure the maximum productivity and well-being of organic dairy cattle.

\section{ACKNOWLEDGMENTS}

The authors express gratitude to Darin Huot and coworkers at University of Minnesota West Central Research and Outreach Center, Morris, for their assistance in data collection and care of the animals. Financial support was provided for this project by the Ceres Trust (Chicago, IL) and by the National Institute of Food and Agriculture, United States Department of Agriculture (Washington, DC), under award number 2012-51300-20015.

\section{REFERENCES}

Aungier, S. P. M., J. F. Roche, M. Sheehy, and M. A. Crowe. 2012 Effects of management and health on the use of activity monitoring for estrus detection in dairy cows. J. Dairy Sci. 95:2452-2466. http://dx.doi.org/10.3168/jds.2011-4653. 
Boland, H. T., G. Scaglia, and K. Umemura. 2008. Case study: Impact of horn flies, Haematobia irritans (L.) (Diptera: Muscidae), on the behavior of beef steers. Prof. Anim. Sci. 24:656-660.

Denning, S. S., S. P. Washburn, and D. W. Watson. 2014. Development of a novel walk-through fly trap for the control of horn flies and other pests on pastured dairy cows. J. Dairy Sci. 97:46244631. http://dx.doi.org/10.3168/jds.2013-7872.

Dolecheck, K. A., W. J. Silvia, G. Heersche, Y. M. Chang, D. L. Ray, A. E. Stone, B. A. Wadsworth, and J. M. Bewley. 2015. Behavioral and physiological changes around estrus events identified using multiple automated monitoring technologies. J. Dairy Sci. 98:8723-8731. http://dx.doi.org/10.3168/jds.2015-9645.

Elischer, M. F., M. E. Arceo, E. L. Karcher, and J. M. Siegford. 2013. Validating the accuracy of activity and rumination monitor data from dairy cows housed in a pasture-based automatic milking system. J. Dairy Sci. 96:6412-6422. http://dx.doi.org/10.3168/ jds.2013-6790.

Gregorini, P., B. Dela Rue, M. Pourau, C. Glassey, and J. Jago. 2013 A note on rumination behavior of dairy cows under intensive grazing systems. Livest. Sci. 158:151-156. http://dx.doi.org/10.1016/j. livsci.2013.10.012.

Gregorini, P., B. DelaRue, K. McLeod, C. E. F. Clark, C. B. Glassey, and J. Jago. 2012. Rumination behavior of grazing dairy cows in response to restricted time at pasture. Livest. Sci. 146:95-98. http://dx.doi.org/10.1016/j.livsci.2012.02.020.

Hart, B. L. 1994. Behavioural defense against parasites: Interaction with parasite invasiveness. Parasitology 109:S139-S151. http:// dx.doi.org/10.1017/S0031182000085140.

Heins, B. J., M. I. Endres, J. C. Paulson, and R. D. Moon. 2014. Effect of organic grain supplementation on production, body weight, body condition score, and fatty acid profiles of organic dairy cows. J. Dairy Sci. 97 (E-Suppl. 1):159. (Abstr.)

Kamphuis, C., B. DelaRue, C. R. Burke, and J. Jago. 2012. Field evaluation of 2 collar-mounted activity meters for detecting cows in estrus on a large pasture-grazed dairy farm. J. Dairy Sci. 95:30453056. http://dx.doi.org/10.3168/jds.2011-4934.

Littell, R. C., P. R. Henry, and C. B. Ammerman. 1998. Statistical analysis of repeated measures data using SAS procedures. J. Anim. Sci. 76:1216-1231.

Mays, A. R., M. A. Brown, D. L. von Tunglen, and C. F. Rosenkrans. 2014. Milk production traits of beef cows as affected by horn fly count and sire breed type. J. Anim. Sci. 92:1208-1212. http:// dx.doi.org/10.2527/jas.2013-7147.

Schirmann, K., M. G. von Keyserlingk, D. M. Weary, D. M. Veira, and W. Heuwieser. 2009. Technical note: Validation of a system for monitoring rumination in dairy cows. J. Dairy Sci. 92:6052-6055. http://dx.doi.org/10.3168/jds.2009-2361.

Schmidtmann, E. T., M. E. Valla, and L. E. Chase. 1981. Effect of face flies on grazing time and weight gain in dairy heifers. J. Econ. Entomol. 74:33-39. http://dx.doi.org/10.1093/jee/74.1.33.

Sorge, U. S., R. D. Moon, B. E. Stromberg, S. L. Schroth, L. Michels, L. J. Wolff, D. F. Kelton, and B. J. Heins. 2015. Parasites and parasite management practices of organic and conventional dairy herds in Minnesota. J. Dairy Sci. 98:3143-3151. http://dx.doi. org/10.3168/jds.2014-9031.

Taylor, D. B., R. D. Moon, and D. R. Mark. 2012. Economic impact of stable flies (Diptera: Muscidae) on dairy and beef cattle production. J. Med. Entomol. 49:198-209. http://dx.doi.org/10.1603/ ME10050.

USDA-NOP (National Organic Program). 2015. The Program Handbook: Guidance and Instructions for Accredited Certifying Agents and Certified Operations. Accessed Feb 25, 2015. http://www.ams. usda.gov/about-ams/programs-offices/national-organic-program

Watson, D. W., S. M. Stringham, S. S. Denning, S. P. Washburn, M. H. Poore, and A. Meier. 2002. Managing the horn fly (Diptera: Muscidae) using an electric walk-through fly trap. J. Econ. Entomol. 95:1113-1118. http://dx.doi.org/10.1603/0022-0493-95.5.1113. 